\title{
Age-Related Differences in Breast Cancer Treatment
}

\author{
David A. August, MD, Thomas Rea, MD, and Vernon K. Sondak, MD
}

Background: More than half of the cases of breast cancer treated in the United States occur in women over age 65. This study investigates age-related differences in breast cancer therapy.

Methods: A retrospective review of all women with primary operable invasive breast cancer treated at the University of Michigan Breast Care Center over a 30-month period showed a total of 77 older patients aged $\geqslant 65$ years (median, 71; oldest patient, 92) for whom full information was available regarding comorbidity, tumor stage and histology, and details of surgery, radiation, and chemohormonal therapy and complications. Fifty-one similar younger patients aged 55-64 years (median, 59) were identified for comparison. Patients were classified as either having received standard treatment or nonstandard treatment. Standard therapy was prospectively defined as follows: local/regional-lumpectomy and axillary lymph node dissection plus radiation therapy or modified radical mastectomy; systemic-chemotherapy and/or tamoxifen for stage II disease. A comorbidity score calculated for each patient assigned one point each for nursing home residence, nonambulatory status, recent surgery, and each medical problem requiring drug therapy.

Results: When overall treatment (local/regional plus systemic) was assessed, proportionately fewer older patients (55 of 77 versus 47 of $51 ; p<0.01$ ) received standard treatment. Fewer older than younger patients ( 62 of 77 versus 50 of $51 ; p<0.01$ ) received surgical therapy that included an axillary dissection. A smaller proportion of older patients received radiation therapy following lumpectomy and axillary lymph node dissection (26 of 29 versus 19 of 19; N.S.). Overall, only 59 of 77 older patients versus 50 of 51 younger patients ( $p$ $<0.001)$ received standard local/regional care. Similar proportions of younger and older patients (19 of 22 and 24 of 30 , respectively) received standard systemic therapy for stage II breast cancer, but older patients were less likely to receive chemotherapy than younger patients $(7 \%$ versus $50 \% ; p<0.001)$. Treatment-related complications were not age-related but were more frequent in patients receiving standard treatment than in patients receiving nonstandard treatment ( 45 of 102 versus two of $26 ; p<0.001$ ). Comorbidity score correlated with the use of nonstandard therapy but not with age. The scores for both older and younger patients receiving overall standard treatment were 0.8 versus 1.5 and 1.4 , respectively, in patients receiving nonstandard treatment. Interestingly, explanations for decisions to deviate from standard treatment guidelines were often not identified. Comorbidity was explicitly noted in only one of four younger patients who received nonstandard treatment therapy. In 22 older patients who received nonstandard treatment, comorbidity was cited in eight cases, patient age was cited in six cases, and patient choice was cited in four cases. Follow-up (median, 34 months) did not show that disease-free or overall survival differences were related to age or to treatment (standard versus nonstandard).

Received March 25, 1993; accepted August 4, 1993.

From the Department of Surgery, Division of Surgical Oncology, University of Michigan, Ann Arbor, Michigan, USA.

Address correspondence and reprint requests to David A. August, M.D., Department of Surgery, University of Michigan, TC 2920-0331, 1500 East Medical Center Drive, Ann Arbor, MI 48109-0331, USA.

Presented at the 46th Annual Cancer Symposium of the Society of Surgical Oncology, Los Angeles, March 18-21, 1993. 
Conclusions: These data demonstrate age-related variations in breast cancer treatment in a multidisciplinary breast care unit. Lower complication rates and equivalent short-term outcomes in women who received nonstandard therapy suggest good clinical judgment may have played a role in these differences. Although age-related patient preferences and comorbidity are relevant, the age-related attitudes of caregivers must also be taken into account to fully explain these variations.

Key Words: Breast cancer-Older women-Age-Treatment differences.

Breast cancer is the second leading cause of cancer mortality among women in the United States; for an American woman, the cumulative lifetime risk of being diagnosed with the disease approaches $10 \%(1,2)$. Incidence rates for breast cancer begin to rise at age $\sim 30$ years and continue to increase thereafter. Thus, breast cancer becomes increasingly common with increasing age. It is estimated that half of the women who die from breast cancer are older than age 65 (2). Incidence and mortality data, however, do not reveal the full impact of breast cancer in older women. Because well over half of women aged $\geqslant 65$ years survive their breast cancer (2), many older patients must live with the sequelae of their cancer and its treatment. Breast cancer is a life-threatening, stressful disease. The physical and psychosocial effects of the disease and its treatment begin with diagnosis, continue during therapy, and extend well beyond the completion of active intervention (3-5). As the population ages, the incidence and prevalence of breast cancer continue to rise, and women with breast cancer live longer, the cumulative impact of breast cancer and the sequelae of breast cancer treatment on the lives of the elderly is certain to grow.

Using broad-based epidemiologic methods, investigators have demonstrated that breast cancer treatment decisions are different for younger and older patients. Despite evidence attesting to their safety, the use of "aggressive" standard therapies such as mastectomy (6-9), lumpectomy with radiation therapy $(10,11)$, breast reconstruction (12), and adjuvant systemic therapy (13-16) is less frequent in the care of older women. Furthermore, increasing age correlates with decisions to deviate from "standard" guidelines in the care of older women with breast cancer $(12,17-25)$.

Comorbidity does not fully explain the discordance between breast cancer care received by younger and older women (22). In addition to comorbid disease, other factors must be examined to explain age-related differences in breast cancer therapy, including patient beliefs and values and provider beliefs and biases. Whatever the cause, it is not known whether these age-related deviations from "standard care" result in improved or poorer physical and psychosocial outcomes.

To better understand how age influences the treatment of women with breast cancer, we must look beyond broad patterns of care to determine why individual patients receive various treatments and to determine the effect of those treatment choices on measures of outcome (treatment- and disease-related morbidity and mortality). The current study was undertaken to investigate agerelated breast cancer therapy variations and the reasons for those variations on a case-by-case basis within a multidisciplinary unit specifically dedicated to breast care. This report emphasizes the interrelationships between patient age, therapy decisions, reasons for deviation from "standard therapy," and treatment-related morbidity.

\section{PATIENTS AND METHODS}

A retrospective review of all patients with primary operable invasive breast cancer [American Joint Committee on Cancer (26) stages I and II] treated at the University of Michigan Breast Care Center (BCC) between January 1, 1988 and June 30, 1990 was conducted to identify women aged $\geqslant 65$ years (older patients). A second group including all women aged 55-64 years (younger patients) treated during this same time period and meeting these criteria was also identified. This group of younger patients was chosen for comparison with the older ones because they were also postmenopausal and approaching the age when comorbidity becomes more prevalent. Comorbidity, pathology, stage, treatment, and complication data were analyzed using hospital records, tumor registry information, and a BCC computerized database. 
The $\mathrm{BCC}$ is a multidisciplinary ambulatory care unit dedicated to the evaluation and treatment of benign and malignant breast disease (27). Virtually all of the evaluation and care of women with breastrelated problems seen at the University of Michigan is provided by BCC clinicians. All breast cancer cases are discussed at a weekly multidisciplinary conference attended by surgical oncologists, radiologists, medical oncologists, radiation oncologists, gynecologists, a plastic surgeon, a psychiatrist, nurse specialists, and social workers. Except in rare instances, treatment recommendations made to the patients described in this study represented a consensus opinion of this multidisciplinary team.

For the purposes of this study, the generic approach of BCC clinicians to the treatment of AJCC stage I and stage II invasive breast cancer (26) was used to define standard treatment. Standard therapy was prospectively defined as follows: local/ regional-lumpectomy and axillary lymph node dissection (ALND) plus radiation therapy or modified radical mastectomy (MRM) for stage I and stage II disease; systemic_chemotherapy and/or tamoxifen for stage II disease; overall-both local/regional therapy (including both surgery and radiation) and systemic therapy standard. Any patient not receiving standard therapy was classified as having received nonstandard treatment.

To help analyze the influence of comorbid disease on breast cancer treatment decisions, a comorbidity scale was created. To calculate the comorbidity score for an individual patient, one point each was assigned for nursing home residence, nonambulatory status, recent nonbreast surgery, and each medical problem requiring prescription drug therapy. The maximum score allowed was five. A comorbidity score for each patient was calculated at the time therapy was initiated.

Each patient's inpatient and outpatient record was reviewed to identify any explicitly stated reasons for deviations from standard therapy. To qualify as an explanation for deviation from standard therapy, a factor must have been explicitly identified in a clinician's note as the reason for a particular nonstandard treatment regimen to have been chosen. Factors qualifying as explanations for deviations from standard therapy included comorbidity, patient choice, and patient age. In patients for whom none of these reasons was explicitly stated as the explanation for deviating from standard therapy, the reason was classified as "not specified."

All statistical comparisons were made using the $\chi^{2}$ test, with levels of significance $\leqslant p=0.05$ being considered significant.

\section{RESULTS}

\section{Patients and tumors}

Retrospective review of all patients with primary operable invasive breast cancer treated at the University of Michigan BCC between January 1, 1988 and June 30, 1990 revealed 77 older women aged $\geqslant 65$ years at the time of initial breast cancer treatment (median, 71; oldest patient, 92) for whom information was available regarding comorbidity, tumor stage and histology, details of surgery, radiation, and chemohormonal therapy, and complications of treatment. An additional 51 younger women aged 55-64 years (median, 59) meeting these criteria were identified for comparison. There were no differences between the two groups in pathologic tumor stage (clinical staging of axillary nodes was used for patients who did not undergo ALND), histology, or estrogen receptor status (Table 1).

\section{Local regional treatment}

With standard surgical therapy defined as appropriate local surgery (lumpectomy or mastectomy)

TABLE 1. Tumor characteristics

\begin{tabular}{|c|c|c|}
\hline $\begin{array}{c}\text { Tumor } \\
\text { characteristics }\end{array}$ & $\begin{array}{c}\text { No. of } \\
\text { older patients } \\
(\geqslant 65)\end{array}$ & $\begin{array}{c}\text { No. of } \\
\text { younger patients } \\
(55-64)\end{array}$ \\
\hline \multicolumn{3}{|l|}{ Stage } \\
\hline $\mathrm{T}_{1} \mathrm{~N}_{0} \mathbf{M}_{0}$ & $38(49 \%)$ & $28(55 \%)$ \\
\hline $\mathrm{T}_{1} \mathrm{~N}_{\chi} \mathrm{M}_{0}$ & $9(12 \%)$ & $1(2 \%)$ \\
\hline $\mathrm{T}_{0} \mathrm{~N}_{1} \mathrm{M}_{0}$ & - & $1(2 \%)$ \\
\hline $\mathrm{T}_{1} \mathrm{~N}_{1} \mathrm{M}_{0}$ & $5(6 \%)$ & $8(16 \%)$ \\
\hline $\mathrm{T}_{\mathrm{x}} \mathrm{N}_{1} \mathrm{M}_{0}$ & $1(1 \%)$ & - \\
\hline $\mathrm{T}_{2} \mathrm{~N}_{0} \mathrm{M}_{0}$ & $14(18 \%)$ & $5(10 \%)$ \\
\hline $\mathrm{T}_{2} \mathrm{~N}_{1} \mathrm{M}_{0}$ & $6(8 \%)$ & $7(14 \%)$ \\
\hline $\mathrm{T}_{2} \mathrm{~N}_{x} \mathrm{M}_{0}$ & $4(5 \%)$ & $1(2 \%)$ \\
\hline Stage I & $47(61 \%)$ & $29(57 \%)$ \\
\hline Stage II & $30(38 \%)$ & $22(43 \%)$ \\
\hline \multicolumn{3}{|l|}{ Histology } \\
\hline Invasive ductal & $66(86 \%)$ & $45(88 \%)$ \\
\hline Invasive lobular & $6(8 \%)$ & $2(4 \%)$ \\
\hline Invasive ductal & & \\
\hline and lobular & $4(5 \%)$ & $2(4 \%)$ \\
\hline Papillary & $1(1 \%)$ & $1(2 \%)$ \\
\hline Tubular & - & $1(2 \%)$ \\
\hline \multicolumn{3}{|l|}{ Estrogen receptors } \\
\hline Positive & $44(57 \%)$ & $35(69 \%)$ \\
\hline Negative & $10(13 \%)$ & $9(18 \%)$ \\
\hline Undetermined ${ }^{a}$ & $23(30 \%)$ & $7(14 \%)$ \\
\hline
\end{tabular}

Lymph node status was determined pathologically. Those patients in whom pathologic lymph node information was not available were staged clinically.

${ }^{a}$ Original biopsy performed elsewhere and no tissue available for estrogen receptor determination. 
combined with ALND, older patients were less likely to receive standard surgical therapy than younger patients $(81 \%$ versus $98 \%, p<0.01)(\mathrm{Ta}-$ ble 2).

Of the 42 older patients who underwent lumpectomy, $81 \%$ received radiation therapy; all 20 younger patients who received breast-conserving therapy also received radiation therapy. This difference is statistically significant $(p<0.05)$ (Table 3$)$. Interestingly, older patients were more likely than younger patients to receive breast-conserving therapy (54\% versus $39 \%, p<0.05)$. Standard breastconserving breast cancer treatment was defined as lumpectomy with ALND plus radiation therapy. The greater frequency of breast conservation in older women was attributable primarily to the greater proportion of older women who received nonstandard breast-conserving surgery in the form of lumpectomy without ALND.

Combining surgery and radiation therapy data (Table 3), we found that only $77 \%$ of older patients versus $98 \%$ of younger patients $(p<0.001)$ received standard local/regional treatment (lumpectomy and ALND plus radiation therapy or MRM).

\section{Systemic treatment}

Similar proportions of older patients and younger patients received standard systemic therapy (adjuvant chemotherapy and/or tamoxifen) following surgery for stage II breast cancer ( 24 of 30 older patients versus 19 of 22 younger patients). Older patients, however, were far less likely than younger patients to receive chemotherapy $(7 \%$ versus $50 \%$, $p<0.001$ ).

TABLE 2. Surgery according to age

\begin{tabular}{lcc}
\hline \multicolumn{1}{c}{ Surgery } & $\begin{array}{c}\text { No. of older } \\
\text { patients } \\
(\geqslant 65)\end{array}$ & $\begin{array}{c}\text { No. of younger } \\
\text { patients } \\
(55-64)\end{array}$ \\
\hline $\begin{array}{l}\text { Lumpectomy alone } \\
\text { Lumpectomy/ALND }\end{array}$ & $13(17 \%)$ & $1(2 \%)$ \\
MRM & $29(38 \%)$ & $19(37 \%)$ \\
TM & $33(43 \%)$ & $31(61 \%)$ \\
Standard therapy & $2(3 \%)$ & - \\
Nonstandard therapy & $62(81 \%)^{a}$ & $50(98 \%)^{a}$ \\
\hline
\end{tabular}

Standard surgical therapy was defined as appropriate local surgery (lumpectomy or mastectomy) combined with axillary node dissection. All other surgical treatment was defined as nonstandard.

ALND, axillary lymph node dissection; MRM, modified radical mastectomy; TM, total mastectomy (without axillary lymph node dissection).

${ }^{a}$ Significant difference between older and younger patients, $p<0.01$.
TABLE 3. Local/regional treatment according to age

\begin{tabular}{lcc}
\hline \multicolumn{1}{c}{ Treatment } & $\begin{array}{c}\text { No. of older } \\
\text { patients } \\
(\geqslant 65)\end{array}$ & $\begin{array}{c}\text { No. of } \\
\text { younger } \\
\text { patients } \\
(55-64)\end{array}$ \\
\hline $\begin{array}{l}\text { Lumpectomy/ALND } \\
\text { plus RT, or MRM }\end{array}$ & $59(77 \%)$ & $50(98 \%)$ \\
Lumpectomy alone & $11(14 \%)$ & - \\
Lumpectomy/ALND alone & $3(4 \%)$ & - \\
Lumpectomy plus RT only & $2(3 \%)$ & $1(2 \%)$ \\
Total mastectomy alone & $2(3 \%)$ & - \\
Standard therapy & $59(77 \%)^{a}$ & $50(98 \%)^{a}$ \\
Nonstandard therapy & $18(23 \%)^{a}$ & $1(2 \%)^{a}$ \\
\hline
\end{tabular}

Standard local/regional therapy was defined as lumpectomy and axillary lymph node dissection plus radiation therapy or modified radical mastectomy.

ALND, axillary lymph node dissection; RT, radiation therapy; MRM, modified radical mastectomy.

${ }^{a}$ Significant difference between older and younger patients, $p<0.001$.

\section{Overall treatment}

Assessing overall treatment (local/regional plus systemic), we found that a significantly smaller proportion of older than younger patients received standard treatment $(71 \%$ versus $92 \%, p<0.01)$. This difference was primarily attributable to the fact that a greater proportion of older women did not receive standard local/regional therapy (Table 4).

\section{Comorbidity}

Comorbidity scores did not correlate with age. The mean comorbidity score in older patients was 1.0 ; in younger patients, it was 0.8 . There was a correlation between comorbidity scores and the use of standard versus nonstandard therapy. For patients receiving standard therapy, the mean comorbidity score was 0.8 overall and 0.8 for both older and younger patients. For patients receiving nonstandard therapy, the mean comorbidity score was 1.4 (1.4 for older patients and 1.5 for younger patients).

\section{Complications}

Complications of therapy occurred with equal frequency in both age groups (Table 5). Complications occurred in $26 \%$ of older patients and $35 \%$ of younger patients. The majority of these complications were minor wound infections, postoperative seromas, or radiation therapy-induced superficial skin desquamation. Serious complications were rare in both older and younger patients. The serious complications observed included two episodes of deep venous thrombosis and one episode of neutropenia in older patients, and one episode of deep 
TABLE 4. Overall treatment according to age

\begin{tabular}{lllcc}
\hline $\begin{array}{c}\text { Local } \\
\text { regional }\end{array}$ & Systemic & Overall & $\begin{array}{c}\% \text { of } \\
\text { older patients } \\
(n=77)\end{array}$ & $\begin{array}{c}\% \text { of } \\
\text { younger } \\
\text { patients } \\
(n=51)\end{array}$ \\
\hline Standard & Standard & Standard & $71^{a}$ & $92^{a}$ \\
Standard & Nonstandard & Nonstandard & 5 & 6 \\
Nonstandard & Standard & Nonstandard & $21^{a}$ & $2^{a}$ \\
Nonstandard & Nonstandard & Nonstandard & 3 & 0 \\
\hline
\end{tabular}

Overall treatment was defined as standard if both local/regional treatment was standard (lumpectomy and axillary lymph node dissection plus radiation therapy or modified radical mastectomy) and systemic treatment was standard (tamoxifen or chemotherapy for stage II disease).

${ }^{a}$ Significant difference between older and younger patients, $p<0.01$.

venous thrombosis and six episodes of neutropenia in younger patients. There were no treatmentrelated deaths. When analyzed by type of therapy received, therapy-related complications were more frequent in patients receiving standard treatment versus nonstandard treatment ( $44 \%$ versus $8 \%, p<$ $0.001)$.

\section{Reasons for nonstandard treatment}

A case-by-case analysis of reasons for patients not receiving standard therapy was performed and is summarized in Table 6. One younger patient received nonstandard local/regional treatment because of comorbidity. She had severe obstructive pulmonary disease and could not safely undergo general anesthesia for ALND. Three younger patients did not receive standard systemic therapy for stage II disease; one refused treatment because of an insurance problem (patient choice), and the reason for nonstandard therapy was not specified for the other two patients.

Of the 22 older patients who received nonstan-

TABLE 5. Complications of therapy

\begin{tabular}{lc}
\hline \multicolumn{1}{c}{ Patient category } & $\begin{array}{c}\text { No. of } \\
\text { total with } \\
\text { complications }\end{array}$ \\
\hline Older patients ( $\geqslant 65)$ & $20 / 77(26 \%)$ \\
Younger patients (55-64) & $18 / 51(35 \%)$ \\
Overall standard treatment ${ }^{a}$ & $45 / 102(44 \%)^{b}$ \\
Overall nonstandard treatment & $2 / 26(8 \%)^{b}$ \\
\hline
\end{tabular}

${ }^{a}$ Overall treatment was defined as standard if both local/ regional treatment was standard (lumpectomy and axillary lymph node dissection plus radiation therapy or modified radical mastectomy) and systemic treatment was standard (tamoxifen or chemotherapy for stage II disease).

${ }^{b}$ Significant difference between patients receiving overall standard treatment and patients receiving overall nonstandard treatment, $p<0.001$. dard therapy, age was the reason specified for six. These six patients had a median age of 85 (versus 76 for those older women receiving nonstandard treatment in whom age was not given as the reason). Although it was not specifically stated, it appears that reluctance to subject these women to general anesthesia played a role in their receipt of nonstandard treatment, since none of them underwent ALND or a procedure requiring general anesthesia. For eight older patients, comorbidity was cited as the reason for nonstandard care. Five of these patients did not receive radiation therapy following lumpectomy because of impaired mobility. Two others underwent lumpectomy and radiation therapy and received tamoxifen; cardiovascular disease was identified as the reason for not undertaking ALND. The eighth patient received neither radiation therapy nor systemic therapy following lumpectomy and ALND (one of six nodes positive) because of her inability to reliably return for followup. Of the remaining eight older patients who received nonstandard therapy, four refused recommended standard treatment and in four the reason was not specified.

Short-term follow-up (median, 34 months) did not reveal any differences in either disease-free or overall survival between older patients and younger patients or between those patients receiving standard or nonstandard treatment (Table 7).

TABLE 6. Reasons for nonstandard therapy

\begin{tabular}{lcc}
\hline \multicolumn{1}{c}{ Reason } & $\begin{array}{c}\text { No. of } \\
\text { older patients } \\
(\geqslant 65)\end{array}$ & $\begin{array}{c}\text { No. of } \\
\text { younger patients } \\
(55-64)\end{array}$ \\
\hline Age & 6 & \\
Comorbidity & 8 & 1 \\
Patient choice & 4 & 1 \\
Not specified & 4 & 2 \\
\hline
\end{tabular}


TABLE 7. Current breast cancer status

\begin{tabular}{lcccc}
\hline $\begin{array}{c}\text { Current } \\
\text { status }\end{array}$ & $\begin{array}{c}\text { No. of } \\
\text { older patients } \\
(\geqslant 65)\end{array}$ & $\begin{array}{c}\text { No. of } \\
\text { younger patients } \\
(55-64)\end{array}$ & $\begin{array}{c}\text { No. receiving } \\
\text { standard treatment }\end{array}$ & $\begin{array}{c}\text { No. receiving } \\
\text { nonstandard treatment }\end{array}$ \\
\hline Alive, no cancer & $59(77 \%)$ & $42(80 \%)$ & $81(79 \%)$ & $20(77 \%)$ \\
Dead, no cancer & $7(9 \%)$ & $2(4 \%)$ & $5(5 \%)$ & $4(15 \%)$ \\
Alive, cancer & $6(8 \%)$ & $4(8 \%)$ & $9(9 \%)$ & $1(4 \%)$ \\
Dead, cancer & $5(6 \%)$ & $3(6 \%)$ & $7(7 \%)$ & $1(4 \%)$ \\
\hline
\end{tabular}

\section{DISCUSSION}

Because half of all breast cancer deaths in the United States occur in women over the age of 65 years $(1,2)$, breast cancer may be thought of as primarily a disease of older women. Unfortunately, older women generally have been underrepresented in many of the prospective, randomized trials that established the principles of breast cancer treatment $(2,28)$. Epidemiologic data, however, demonstrate that older women with breast cancer receive different diagnostic and therapeutic interventions than do similarly afflicted younger women (18-25). In light of these facts, we set out to answer the following three questions: First, in a specialized, multidisciplinary unit dedicated to the treatment of breast disease, do older women (age $\geqslant 65$ years) receive different treatment from younger women? Second, if there are age-related treatment differences, what are the factors that contribute to these variations? Finally, what are the effects of agerelated treatment variations on disease- and treatment-related morbidity and mortality?

The data presented demonstrate that even in a specialized, multidisciplinary unit dedicated to the treatment of breast disease, there are clear differences in the treatment older and younger women receive for primary operable (stage I and II) invasive breast cancer. Older patients were less likely to receive standard surgical therapy, less likely to receive radiation therapy following lumpectomy, and less likely to receive standard local/regional treatment (lumpectomy, ALND, plus radiation therapy or modified radical mastectomy). Although older and younger women were equally likely to receive adjuvant systemic therapy in the presence of stage II disease, the older women were more likely to receive tamoxifen only (rather than chemotherapy). These differences in various components of breast cancer therapy meant that overall, whereas $92 \%$ of women under the age of 65 years received standard treatment, only $71 \%$ of older women received standard treatment. These differences were observed even though the two groups in this study were selected to avoid variables confounding age-related factors. Tumor stage, pathology, and receptor status were comparable. The younger women (aged 55-64) were all postmenopausal. Furthermore, general comorbidity was comparable between younger and older patients.

The age-related differences in treatment must be considered in the light of the following two facts: (a) Few older women have been included in definitive breast cancer treatment trials $(2,28)$; and (b) studies suggest that age does not influence either the efficacy or toxicity of surgery, radiation therapy, or chemohormonal therapy for breast cancer treatment (6-16). Thus, there is little evidence to suggest that older women should be treated differently from younger women. Nevertheless, age-related treatment differences are not limited to the present study; they have also been reported by other investigators.

To better understand the basis for these agerelated differences in breast cancer treatment, we looked at some general and individual factors that might have influenced breast cancer treatment choices. Comorbidity did not play a major role in choices to deviate from standard therapy. Generally, comorbidity scores were comparable between women in the two groups. The presence of comorbid diseases was cited as the reason to use nonstandard treatment in approximately one-quarter of the younger patients and one-third of the older patients who did not receive standard therapy. Similarly, although patient choices occasionally resulted in the use of nonstandard therapy, older women were no more likely than younger women to decline standard treatment. The striking difference in reasons to forgo standard treatment in individual cases was the identification of age as the primary indication for nonstandard treatment in $27 \%$ of older women not receiving standard treatment. Thus, chronologic (as opposed to physiologic) age was a significant factor that influenced physician recommendations to patients concerning optimal breast 
cancer treatment. In the absence of clinical data to support the use of chronologic age as a predictor of response to therapy or of the likelihood of complications, it is equally plausible to attribute this age effect to physician bias ("ageism") or exercise of good clinical judgment.

To analyze the possible role of physician bias and clinical judgment on decisions to treat older and younger patients differently, we assessed the relationship of treatment-associated complications and disease outcomes to treatment choices. In both older and younger patients, the mean comorbidity score was higher in women who received nonstandard treatment than in those who received standard treatment; this suggests that clinical judgment played at least some role in choices to deviate from standard care.

Complication rates were comparable between older and younger women, but they were clearly higher in women who received standard care; again, clinical judgment appears to play a role in avoiding some complications. Of the 10 serious complications observed, nine were attributable to systemic chemotherapy. This finding may have influenced some decisions to avoid chemotherapy in older women. The more frequent use of nonstandard care in older patients also correlated with the more frequent use of breast-conserving therapy. Disease outcomes (i.e., recurrence and survival) with a median follow-up of 34 months were similar for both groups, indicating that at least in the short term, choices in favor of nonstandard care did not adversely affect treatment results. Thus, there is ample evidence to suggest that good clinical judgment played a substantial role in age-related differences in breast cancer treatment decisions. Nevertheless, a case-by-case analysis clearly demonstrated that age in and of itself also biased treatment recommendations.

In toto, these data may be interpreted in at least two alternative fashions. Given that age in and of itself was not predictive of treatment- or diseaserelated morbidity or mortality, one could argue that chronologic age not be allowed to influence breast cancer treatment recommendations to patients. Standard therapy should be offered to all patients, regardless of age, in the absence of specific contraindications (comorbidity or strong, informed patient preference). Alternatively, given a greater frequency of breast-conserving therapy in older women and equivalent disease outcomes and fewer complications in women receiving nonstandard therapy (and presumably less treatment-related discomfort and inconvenience in this less aggressively treated group of women), clinicians should be encouraged to exercise their clinical judgment more frequently to recommend nonstandard treatment to both older and younger women.

It may in fact be the case that women of all ages should be receiving less therapy than is currently standard. Treatment of breast cancer has evolved dramatically over the past 2 decades and will undoubtedly continue to change over the next 10 years. These changes may direct us to more "nonstandard," less aggressive treatment for most women with breast cancer. An informed choice between more standard or more nonstandard treatment must await clinical trials to determine the relative merits of broadly applied standard treatment protocols versus individualized treatment planning not only based on trial-proven therapeutic approaches but also allowing for clinical judgment and physician bias.

Whether or not breast cancer treatment recommendations should differ according to patient age, it is clear that older women assess treatment options presented to them differently. Using open-ended interviews, Peters (29) explored the breast cancer beliefs of a group of older breast cancer patients (mean age, 60 years; range, 49-80). Patients viewed themselves as passive victims of causative agents. Although nearly all expressed confidence in their physicians, $89 \%$ believed that their prognosis was dependent upon God. Over 90\% identified the inability to care for themselves and perform everyday tasks as the worst aspects of their illness. Passivity in older women with breast cancer has also been observed by other investigators $(30,31)$. These findings suggest that two important factors are relevant to breast cancer treatment in older women. First, the confidence (blind faith?) of older patients in their physicians indicates that patients will listen to, evaluate, and often accept their doctors' recommendations regarding the safety and benefits of therapeutic alternatives. Second, the concern of older patients over their ability to care for themselves and perform habitual tasks highlights their potential reluctance to undergo standard therapy unless their physicians take the time to thoroughly discuss options and consequences with them.

In summary, these data demonstrate clear agerelated variations in breast cancer treatment within a dedicated, multidisciplinary breast care unit. Lower complication rates and equivalent short- 
term outcomes in women receiving nonstandard therapy suggest that good clinical judgment plays a role in these differences. Although case-by-case analysis also indicates that age-related patient preferences and comorbidity are relevant, chronologic age is also a factor that must be considered to fully account for these variations.

\section{REFERENCES}

1. Boring CC, Squires TS, Tong T. Cancer statistics, 1991. Ca Cancer J Clin 1991;41:19-36.

2. Stewart JA, Foster RS. Breast cancer and aging. Semen Oncol 1989;16:41-50.

3. Vinokur AD, Threatt BA, Caplan RD, Zimmerman BL. Physical and psychosocial functioning and adjustment to breast cancer. Long-term follow-up of a screening population. Cancer 1989;63:394 405.

4. Vinokur AD, Threatt BA, Vinokur-Kaplan D, Satariano WA. The process of recovery from breast cancer for younger and older patients. Changes during the first year. Cancer 1990;65:1242-54.

5. Vinokur AD, Vinokur-Kaplan D. "In sickness and in health." Patterns of social support and undermining in older married couples. J Aging Health 1990;2:215-41.

6. Davis SJ, Karrer FW, Moor BJ, Rose SG, Eakins G. Characteristics of breast cancer in women over 80 years of age. Am J Surg 1985;150:655-8.

7. Robins RE, Lee D. Carcinoma of the breast in women 80 years of age and older: still a lethal disease. Am $J$ Surg 1985;149:606-9.

8. Hunt KE, Fry DE, Bland KI. Breast carcinoma in the elderly patient: an assessment of operative risk, morbidity and mortality. Am I Surg 1980;140:339-42.

9. Herbsman H, Feldman J, Seldera J, Gardner B, Alfonso A. Survival following breast cancer surgery in the elderly. Cancer 1981;47:2358-63.

10. Kantrowitz DA, Poulter CA, Sischy B, et al. Treatment of breast cancer among elderly women with segmental mastectomy plus postoperative radiotherapy. Int I Radiat Oncol Biol Phys 1988;15:263-70.

11. Toonkel LM, Fix I, Jacobson LH, Bamberg N. Management of elderly patients with primary breast cancer. Int $I$ Radiat Oncol Biol Phys 1988;14:677-81.

12. Handel N, Silverstein MJ, Waisman E, Waisman J. Reasons why mastectomy patients do not have breast reconstruction. Plast Reconstr Surg 1990;86:1118-22.

13. Begg CB, Carbone PP. Clinical trials and drug toxicity in the elderly. The experience of The Eastern Cooperative Oncology Group. Cancer 1983;52:1986-92.
14. Walsh SJ, Begg CB, Carbone PP. Cancer chemotherapy in the elderly. Semin Oncol 1989;16:66-75.

15. Castiglione M, Gelber RD, Goldhirsch A. Adjuvant systemic therapy for breast cancer in the elderly: competing causes of mortality. J Clin Oncol 1990;8:519-26.

16. Allen C, Cox EB, Manton KG, Cohen HJ. Breast cancer in the elderly. Current patterns of care. J Am Geriatr Soc 1986; $34: 637-42$.

17. Schain WS. Reasons why mastectomy patients do not have breast reconstruction (discussion). Plast Reconstr Surg $1990 ; 86: 1123-5$

18. Chu J, Diehr P, Feigel P, et al. The effect of age on the care of women with breast cancer in community hospitals. $J$ Gerontol 1987;42:185-90.

19. Silliman RA, Guadagnoli E, Weitberg AB, et al. Age as a predictor of diagnostic and initial treatment intensity in newly diagnosed breast cancer patients. $J$ Gerontol $1989 ; 44$ : M46-50.

20. Samet J, Hunt WC, Key C, Humble CG, Goodwin JS Choice of cancer therapy varies with age of patient. JAMA $1986 ; 255: 3385-90$

21. Becker TM, Goodwin JS, Hunt WC, Key CR, Samet JM. Survival after cancer surgery of elderly patients in New Mexico. I Am Geriatr Soc 1989;37:155-9.

22. Greenfield S, Blanco DM, Elashoff RM, Ganz PA. Patterns of care related to age of breast cancer patients. JAMA 1987 ; 257:2766-70.

23. Schleifer SJ, Bhardwaj S, Lebovits A, Tanaka JS, Messe M, Strain JJ. Predictors of physician nonadherence to chemotherapy regimens. Cancer 1991;67:945-51.

24. Bergman L, Dekker G, van Leeuwen FE, Huisman SJ, van Dam FSAM, Van Dongen JA. The effect of age on treatment choice and survival in elderly breast cancer patients. Cancer 1991;67:2227-34

25. Swanson GM, Satariano ER, Satariano WA, Osuch JR. Trends in conserving treatment of invasive carcinoma of the breast in females. Surg Gynecol Obstet 1990;171:465-71.

26. Beahrs OH, Henson DE, Hutter RVP, Myers MH. Manual for staging of cancer. 3rd ed. Philadelphia: Lippincott, 1988: 145-50.

27. August DA, Carpenter LC, Harness JK, et al. The benefits of a multidisciplinary approach to breast care. $J$ Surg Oncol $53: 161-7,1993$.

28. Yancik $Y$, Ries LG. Cancer in the aged. An epidemiologic perspective on treatment issues. Cancer 1991;68:2502-10.

29. Peters $\mathbf{H}$. Breast cancer: lay notions and coping strategies. Master's thesis, University of North Carolina, Chapel Hill, 1976.

30. Westbrook MT, Viney LL. Age and sex differences in patients' reactions to illness. J Health Soc Behav 1983;24:313-24.

31. Kohn M, Menon G. Life prolongation: views of elderly outpatients and health care professionals. I Am Geriatr Soc $1988 ; 36: 840-4$. 